narrowing, the patient is considered for arteriography. This is only done when there would be no contra-indication to operation. Thompson makes a good case for operating even when the patient is asymptomatic, as the chances of the patient developing symptoms later are very great.

The cumulative number system of classification (Chapter 17) as applied to stroke is an interesting concept which, if it could be more universally accepted, would allow multi-centre trials to be more easily organized and elucidated. Clinical trials of various forms of management are discussed. There is also an interesting series of chapters on non-invasive assessment of carotid artery disease. The book ends with a series of papers on intracranial surgery for stroke which is a form of therapy that is developing rapidly and may become increasingly used.

This book can be recommended to the wide range of doctors who are involved in the management of patients with strokes.

\section{Treatment of Common Acute Poisonings (4th edn)}

By H. Matthew and A. A. H. Lawson. Pp. $x+210$. Churchill Livingstone, Edinburgh, London and New York. $£ 6.00$.

When the first edition of this book appeared in 1967 there is no doubt, as the authors emphasize, that dangerous misconceptions about the management of acute poisonings were rife. But a fresh outlook was already being directed to the subject, notably by Clemmesen in Denmark and by Lockit in England. Building on this basis the Edinburgh team under Matthew thoroughly integrated the philosophy for the clinician and, as a result, a more enlightened attitude not only spread but was also profitably adopted.

Today that proselytizing is no longer imperative and the pragmatic sermon has less of a place. Rather should there be a consolidation; with guidance to the audience in the direction of the latest advances that appear to be promising for practice. In this light, parts of this latest fourth edition parade somewhat self-consciously. Thus, with the statistics, surely the graph of admissions to the Royal Infirmary, Edinburgh (progressively taller and narrower each time it is reproduced) has become a little out of date, ending as it does in 1973. Much more recent and relevant figures are obtainable, nationally too, which almost impertinently reveal that, for all our efforts, the overall deaths from poisoning remain unchecked over recent decades. And whilst the barbiturates have retreated in the face of righteous pressure the antidepressants have just as adequately taken their place as 'captains of the toxic men of death'.

Similarly, the section on the place of the laboratory includes some generalizations, not merely about analysis but also about pharmacokinetics and pharmodynamics that hardly withstand measured criticism.

Then the final chapters on drug addiction and prevention are, sadly, little more than perfunctory. Either these topics should be tackled resolutely and in an informed manner or, perhaps better still in a small book, omitted altogether.

Harsh as some of this criticism may appear it is confined to a relatively small part of the work. The clinical sections making up the bulk of the text are still very worthwhile and any doctor who wants to keep himself informed of acute poisoning in the practical sense could do no better than keep this volume by him. 